\title{
Research on the Intrinsic Motivation and Safety Performance of Aircraft Maintenance Personnel: Based on Empirical Analysis
}

\author{
Yilin She \\ School of Management, Wuhan University of Technology, Wuhan, P.R.China, 430070 \\ sheyilin@foxmail.com
}

\begin{abstract}
Keywords: Intrinsic Motivation; Safety Performance; Aircraft Maintenance Personnel; Difference Analysis
\end{abstract}

\begin{abstract}
In order to improve the performance level of aircraft maintenance personnel, by the way of questionnaire survey, collecting sample data for statistical analysis. this paper analyzes the relationship between the intrinsic motivation and safety performance of the aircraft maintenance personnel, and compares these two variables by grouping different control variables, finally, through the above analysis, the conclusion is drawn that there is a great correlation between the intrinsic motivation and safety performance of the aviation maintenance personnel, the results of a number of differential analyses support this conclusion, the management countermeasures to improve the safety performance of air aircraft maintenance personnel also be put forward.
\end{abstract}

\section{Introduction}

With the rapid development of China's economy, innovation of science and technology. Civil aviation industry has developed rapidly. This development creates opportunities for civil aviation, also brought a challenge. Aviation safety becomes more important. The increasing of aviation traffic puts forward higher requirements for the maintenance personnel. This research focus on the influence of intrinsic motivation on safety performance of maintenance personnel and difference of demographic variables on this variables.

Safety Performance. The safety performance is divided into personal safety performance and organizational safety performance. The definition of personal safety performance is put forward by Neal and Griffin [1], the definition is the evaluation of job security is related to the work behavior. According to the different opinions of scholars, safety performance can roughly divided into the following three categories: the first category is the specific performance evaluation to evaluate the safety and safety performance; the second is the use of performance and safety accident consequence assessment [2]; the third category is a combination of safety accidents and the consequences to measure safety performance [3].

There are some research about the factors affect the performance of safety, these topic are mainly around the safety climate, safety culture, the three factors which influence the safety attitude on safety performance to expand, and. Such as Morrow S (2014) presented a unique look at safety culture across the United States nuclear power industry and takes a critical step toward establishing that safety culture is empirically related to safety performance [4]. K Stephanie found safety climate was a full mediator between contingent reward and the three performance behaviors. Chen Y (2017) proposed Safety climate affected construction workers' physical safety outcomes as well as their psychological wellbeing [5].

Intrinsic Motivation. Hertz Berg first put forward the theory of hygiene-motivational factors incentive in 2003 and explain the intrinsic meaning of motivation: can bring positive attitude, satisfaction and can meet the needs of self-realization factor called incentive factors. Its content includes: sense of honor, achievement, challenging work, increased job responsibilities and opportunities for growth and development [6].

Hygiene-motivational factors theory is constantly enriched and deepened [7], and it is generally believed that the source of intrinsic motivation is the satisfaction of internal needs. Intrinsic motivation 
refers to the creation of motivation from the individual or the activity itself, such as satisfaction, personal honor, job challenge, autonomy [8], etc. Intrinsic motivation is more reflected in the work of their own interest and enjoyment. Intrinsic motivation can have a positive impact on employee behavior, performance, and work environment. Some scholars pointed out that if the employee because of interest rather than work, and the staff brought about the challenge that make working feel pleasure [9], so the work itself can be thought of as an incentive, that is the inner motivation. Flannery M (2017) found intrinsic motivation is associated with improved well-being and sustained behavioral change. The above studies fully explain what intrinsic motivation is. This paper is based on the definition of intrinsic motivation [10].

Hypothesis. Based on the discussion above, the following hypotheses are put forward, Motivation is the antecedent variable, Safety Performance is the outcome variable, Intrinsic motivation contains four dimensions: job autonomy, promotion expectations, supervisor support, person-organization Fit on organization value; safety performance contains four dimensions: safety behavior, safety responsibility, safety training. As shown in the following fig.1.

H1: Intrinsic motivation has a significant positive effect on safety performance

$\mathrm{H} 2$ : There are obvious differences in intrinsic motivation and safety performance grouping by different control variables

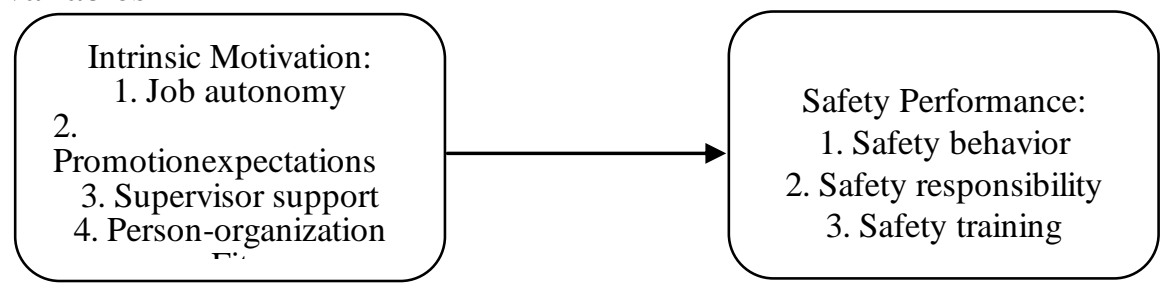

Figure 1. Hypothetical model

\section{Data and Methodology}

Sample. This research collected 158 questionnaires completed by the maintenance personnel from seven different airlines and airports including 125 valid questionnaires. In the sample, there were 100 men, making up 80 percent of the total, 25 women and 20 percent of the total. The number of people under the age of 20 is 11, accounting for 8.8 percent, 21 to 30 years old is 61 , accounting for 48 percent, 31 to 40 years old is 35 , accounting for 28 percent, 40 to 51, 12 people, accounting for 9.6 percent, and 4.8 percent of people over 51 years of age. In terms of education, the number that education below junior college is 9 , accounting for $7.2 \%$, the number that record of formal schooling is college is 50 , accounting for $40 \%$, undergraduate is 61 , accounting for $48.8 \%$, record of formal schooling is master degree and higher is 5 , accounting for $4 \%$. From the above demographic characteristics, this sample has a good representation, as shown in table 1 .

Table 1 The basic characteristics description of sample

\begin{tabular}{|c|c|c|c|}
\hline \multicolumn{2}{|c|}{ Demographic variables } & frequency & Percent \\
\hline \multirow{2}{*}{ gender } & male & 100 & $80 \%$ \\
\hline & female & 25 & $20 \%$ \\
\hline \multirow{5}{*}{ age } & $<20$ & 11 & $8.8 \%$ \\
\hline & $21-30$ & 61 & $48 \%$ \\
\hline & $31-40$ & 35 & $28 \%$ \\
\hline & $40-51$ & 12 & $9.6 \%$ \\
\hline & $>51$ & 6 & $4.8 \%$ \\
\hline \multirow{4}{*}{ Record of formal schooling } & Lower than college & 9 & $7.2 \%$ \\
\hline & College & 50 & $40 \%$ \\
\hline & Undergraduate course & 61 & $48.8 \%$ \\
\hline & master's degree and higher & 5 & $4 \%$ \\
\hline Total & 12 & & \\
\hline
\end{tabular}


Variable Measurement. The intrinsic motivation scale is comprised of the work autonomy scale, the promotion expectation scale, the higher level support scale and the individual and the organization value matching scale. The safety performance of this article includes three dimensions, the employee safety level scale, the employee safety attitude scale, the employee safety training scale.

Descriptive Analysis. Using SPSS21.0 software, the mean and standard deviation of the variables are analyzed. Before data analysis, the reliability and validity of the three scales in questionnaire should be tested separately to ensure that the results of the questionnaire survey were true and reliable. Analysis by importing data into SPSS software, it is found that all the scale has good reliability, and the coefficients $\alpha$ of each dimension in the scale are bigger than 0.8 . As shown in table 2 .

The data shows that job autonomy is at a low level, promotion expectations is at a higher level support, and personal and organizational value matching are at a moderate level. This has to do with the job characteristic of the machine personnel, the working time of the machine personnel is not fixed, the process requirement is strict, and so the work autonomy is low. The results show that the safety behaviors, safety responsibilities and safety training of the personnel are at higher level.

Table 2 Descriptive analysis of all the scale

\begin{tabular}{ccccccc}
\hline \multirow{2}{*}{ Variable } & Dimension & $\begin{array}{c}\text { Sample } \\
\text { number }\end{array}$ & $\begin{array}{c}\text { Number } \\
\text { of items }\end{array}$ & Mean & $\begin{array}{c}\text { Standard } \\
\text { Deviation }\end{array}$ & Cronbach's Alpha \\
\hline \multirow{3}{*}{$\begin{array}{c}\text { Intrinsic } \\
\text { Motivation }\end{array}$} & Work autonomy & 125 & 6 & 2.790 & 1.029 & 0.843 \\
\cline { 2 - 7 } & Promotion expectation & 125 & 3 & 3.341 & 0.893 & 0.812 \\
\cline { 2 - 7 } & Superior support & 125 & 6 & 3.104 & 0.986 & 0.934 \\
\cline { 2 - 7 } & $\begin{array}{c}\text { Person-organization Fit } \\
\text { on organization value }\end{array}$ & 125 & 3 & 3.407 & 0.875 & 0.771 \\
\hline Satisfaction & Job Satisfaction & 125 & 6 & 3.519 & 0.801 & 0.835 \\
\hline \multirow{2}{*}{$\begin{array}{c}\text { Safety } \\
\text { Performance: }\end{array}$} & Safety behavior & 125 & 5 & 3.820 & 0.922 & 0.909 \\
\cline { 2 - 7 } & Safety responsibility & 125 & 3 & 3.950 & 0.896 & 0.848 \\
\cline { 2 - 7 } & Safety training & 125 & 5 & 4.040 & 0.708 & 0.892 \\
\hline
\end{tabular}

Validity of scale. Using exploratory factor analysis for intrinsic motivation scale and safety performance validity scale selected four main factors and three main factors, using the maximum variance method of rotation, the results were satisfactory. As shown in table 3 and table 4.

Table 3 Rotated component matrix of .Intrinsic motivation scale

\begin{tabular}{ccccc}
\hline \multirow{2}{*}{ Item } & \multicolumn{4}{c}{ component } \\
\cline { 2 - 5 } & 1 & 2 & 3 & 4 \\
\hline 1 & .018 & .607 & .277 & .286 \\
\hline 2 & .046 & .641 & .129 & .281 \\
\hline 3 & .116 & .795 & .009 & .233 \\
\hline 4 & .195 & .807 & .082 & .087 \\
\hline 5 & .082 & .754 & .161 & .135 \\
\hline 6 & .091 & .794 & .072 & .002 \\
\hline 7 & .319 & .120 & .303 & .546 \\
\hline 8 & .269 & .145 & .003 & .822 \\
\hline 9 & .219 & .166 & .321 & .712 \\
\hline 10 & .551 & .205 & .371 & .350 \\
\hline 11 & .543 & .141 & .503 & .273 \\
\hline 12 & .716 & .093 & .234 & .317 \\
\hline 13 & .859 & .038 & .146 & .126 \\
\hline 14 & .815 & .072 & .218 & .165 \\
\hline 15 & .797 & .193 & .141 & .103 \\
\hline 16 & .196 & .148 & .797 & .146 \\
\hline 17 & .215 & .125 & .791 & .070 \\
\hline 18 & .362 & .177 & .619 & .228 \\
\hline & & & &
\end{tabular}

Table 4 Rotated component matrix of Safety performance scale

\begin{tabular}{cccc}
\hline \multirow{2}{*}{ Item } & \multicolumn{3}{c}{ component } \\
\cline { 2 - 4 } & 1 & 2 & 3 \\
\hline 1 & .042 & .873 & .112 \\
\hline 2 & .162 & .824 & .272 \\
\hline 3 & .315 & .778 & .030 \\
\hline 4 & .217 & .817 & .239 \\
\hline 5 & .392 & .750 & .172 \\
\hline 6 & .216 & .113 & .844 \\
\hline 7 & .406 & .235 & .775 \\
\hline 8 & .370 & .308 & .705 \\
\hline 9 & .760 & .199 & .301 \\
\hline 10 & .776 & .166 & .331 \\
\hline 11 & .780 & .160 & .244 \\
\hline 12 & .773 & .231 & .224 \\
\hline 13 & .772 & .250 & .125 \\
\hline & & &
\end{tabular}




\section{Results}

Correlation Analysis. Using Pearson product moment correlation coefficient to analyze the correlation between variables, the closer the correlation coefficient is, the stronger the correlation between the variables. And through the analysis of the relevant results between the variables, the hypothesis of this study can be test partially, the correlation coefficients between the variables are shown in the following table 5. Seen from table 5

Table 5 Pearson Correlation among Main Variables

\begin{tabular}{cccccccc}
\hline & $\begin{array}{c}\text { Work } \\
\text { autonomy }\end{array}$ & $\begin{array}{c}\text { Promotio } \\
\text { expectatio } \\
\mathrm{n}\end{array}$ & $\begin{array}{c}\text { Superior } \\
\text { support }\end{array}$ & $\begin{array}{c}\text { Person-organizatio } \\
\mathrm{n} \text { Fit on } \\
\text { organization value }\end{array}$ & $\begin{array}{c}\text { Safety } \\
\text { behavior }\end{array}$ & $\begin{array}{c}\text { Safety } \\
\text { responsibility }\end{array}$ & $\begin{array}{c}\text { Safety } \\
\text { training }\end{array}$ \\
\hline Work autonomy & 1 & .181 & .151 & $.373^{* *}$ & .088 & $.361^{* *}$ & .067 \\
\hline $\begin{array}{c}\text { Promotion } \\
\text { expectation }\end{array}$ & 1 & $.624^{* *}$ & .082 & $.480^{* *}$ & $.198^{*}$ & $.414^{* *}$ \\
\hline Superior support & & 1 & $.627^{* *}$ & .105 & .215 & .182 \\
\hline $\begin{array}{c}\text { Person-organization } \\
\text { Fit }\end{array}$ & & & 1 & $.478^{*}$ & $.445^{*}$ & $.219^{* *}$ \\
\hline Safety behavior & & & & & & .096 & $.131^{*}$ \\
\hline Safety responsibility & & & & & & & $.658^{* *}$ \\
\hline Safety training & & & & & & 1 \\
\hline
\end{tabular}

Seen from the result of Pearson correlation among main variables, some conclusions can be found. There is no significant correlation between the dimensions of intrinsic motivation. There is a certain correlation among the dimensions of safety performance, and there is a positive correlation between intrinsic motivation and safety performance. At this point, hypothesis 1 have passed the test.

Difference Analysis. Using SPSS21.0 software, According to gender, age, educational background grouping the sample, using independent sample T-test and one-way Anova test to explore the difference of the different nature of the sample statistic results obtain the following results, as shown in Table 6.

Table 6 the Result of Difference Analysis

\begin{tabular}{|c|c|c|c|c|}
\hline \multirow{2}{*}{ variable } & \multirow{2}{*}{ dimension } & \multirow{2}{*}{ Group with differences } & \multicolumn{2}{|c|}{ Test Result } \\
\hline & & & $\mathrm{F}$ & Sig. \\
\hline \multirow{4}{*}{$\begin{array}{c}\text { Intrinsic } \\
\text { Motivation }\end{array}$} & Job autonomy & age & 4.759 & 0.001 \\
\hline & Promotion expectations & gender & -2.972 & .0006 \\
\hline & Supervisor support & educational background & 4.371 & 0.006 \\
\hline & Person-organization Fit on organization value & Work unit type & .128 & 0.042 \\
\hline \multirow{3}{*}{$\begin{array}{c}\text { Safety } \\
\text { Performanc } \\
\text { e }\end{array}$} & Safety behavior & none & & \\
\hline & Safety responsibility & none & & \\
\hline & Safety training & gender & 12.856 & 0.001 \\
\hline
\end{tabular}

It can be seen from table 6 that there are differences in autonomy of work at different ages, the older the age, the higher the autonomy of the work. Men have higher expectations of promotion than women. The higher the educational degree, the easier it is to gain the support of the superior. There was no significant difference in all group's safety behavior and safety responsibility, but in terms of safety training performance, men are superior to women. Thus, $\mathrm{H} 2$ is partially validated.

\section{Conclusion}

This paper took intrinsic motivation influence on maintenance personnel safety performance as the core research content, at the same time, the difference of different demographic variables group is considered. 
Using the methods of deduction, questionnaire survey and statistical analysis to study the relationship among these variables. Study found that: The safety performance of the maintenance personnel is positively affected by the intrinsic motivation, and different demographic variables group have obvious differences in some dimensions.

In practical application significance, this study expected that improve intrinsic motivation can enhance safety performance and improve safety level. On the one hand, Aviation maintenance personnel is typical technical staff, there is a problem of narrow path to promotion, therefore the implementation of technology and management of double-track promotion mechanism greatly promoted the maintenance personnel promotion space, make its can choose their suitable sequence development, also can switch between the two sequences, cultivating maintenance personnel ability in many aspects. On the other hand, the study found that aviation personnel were generally less empowered, the aircraft maintenance personnel have a fixed workflow, but not fixed at the end of the work, they faced more accidents and more difficult working conditions, therefore, in terms of job autonomy, improving working conditions for aircraft maintenance personnel, using a more humane, shifts and transfer system, training system and so on, the above measures can make work time more controllable and freedom.

In the next step in the study, the process indicators of safety performance should be considered, In addition, the scale used in this paper is a scale developed by foreign scholars, and some problems are not suitable for the national conditions in China and need to be further verified.

\section{References}

[1] A Neal, M A Griffin, P M Heart, The Impact of Organizational Climate on Safety Climate and Individual Behavior, J Safety Science, 34(2000):99-109

[2] S W Zhang, The Relationship of Organizational Climate and Safety Performance J .Enterprise Economy, 285(2004):28-29 (In Chinese)

[3] D Zohar. The Effects of Leadership Dimensions, Safety Climate, and Assigned Priorities on Minor Injuries in Work Group Journal of Organizational Behavior, 33(2002):231-243.

[4] S L Morrow, G K Koves, V E Barnes. Exploring the Relationship between Safety Culture and Safety Performance in U.S. Nuclear Power Operations J. Safety Science, 69(2014):37-47.

[5] Y Chen, B McCabe, D Hyatt. Impact of Individual Resilience and Safety Climate on Safety Performance and Psychological Stress of Construction Workers: A Case Study of the Ontario Construction Industry J. Journal of Safety Research, 61(2017):167-176.

[6] F aramillo, W B Locander, P E Spector, et al. Getting the Job Done: The Moderating Role ofInitiative on the Relationship between Intrinsic Motivation and Adaptive Selling J. Journal of Personal Selling \& Sales Management, 27(2013):59-74.

[7] R Khalaila. The Relationship between Academic Self-concept, Intrinsic Motivation, Test Anxiety, and Academic Achievement among Nursing Students: Mediating and Moderating Effects. J. Nurse Education Today, 35(2014):432-8.

[8] A Ruffault, M Bernier, N Juge, et al. Mindfulness May Moderate the Relationship between Intrinsic Motivation and Physical Activity: A Cross-Sectional Study J. Mindfulness, 7(2016):445-452.

[9] Guo Y, Liao J, Liao S, et al. The Mediating Role of Intrinsic Motivation on the Relationship between Developmental Feedback and Employee Job Performance [J]. Social Behavior \& Personality an International Journal, 42(2014):731-741(11).

[10] Flannery M. Self-Determination Theory: Intrinsic Motivation and Behavioral Change J. Oncology Nursing Forum, 44(2017):155. 